Federal Reserve Bank of Minneapolis

Research Department Staff Report 217/JV

\title{
Sticky Price Models of the Business Cycle: Can the Contract Multiplier Solve the Persistence Problem?*
}

\author{
V. V. Chari \\ University of Minnesota \\ and Federal Reserve Bank of Minneapolis \\ Patrick J. Kehoe \\ University of Pennsylvania \\ Federal Reserve Bank of Minneapolis \\ and National Bureau of Economic Research \\ Ellen R. McGrattan \\ Federal Reserve Bank of Minneapolis
}

\begin{abstract}
We construct a quantitative equilibrium model with firms setting prices in a staggered fashion and use it to ask whether monetary shocks can generate business cycle fluctuations. These fluctuations include persistent movements in output along with the other defining features of business cycles, like volatile investment and smooth consumption. We assume that prices are exogenously sticky for a short time. Persistent output fluctuations require endogenous price stickiness in the sense that firms choose not to change prices much when they can do so. We find that for a wide range of parameter values, the amount of endogenous stickiness is small. Thus, we find that in a standard quantitative model, staggered price-setting, alone, does not generate business cycle fluctuations.

*The views expressed herein are those of the authors and not necessarily those of the Federal Reserve Bank of Minneapolis or the Federal Reserve System.
\end{abstract}




\title{
STICKY PRICE MODELS OF THE BUSINESS CYCLE: CAN THE CONTRACT MULTIPLIER SOLVE THE PERSISTENCE PROBLEM?
}

\author{
By V. V. Chari, Patrick J. Kehoe, and Ellen R. McGrattan $^{1}$
}

\begin{abstract}
We construct a quantitative equilibrium model with firms setting prices in a staggered fashion and use it to ask whether monetary shocks can generate business cycle fluctuations. These fluctuations include persistent movements in output along with the other defining features of business cycles, like volatile investment and smooth consumption. We assume that prices are exogenously sticky for a short time. Persistent output fluctuations require endogenous price stickiness in the sense that firms choose not to change prices much when they can do so. We find that for a wide range of parameter values, the amount of endogenous stickiness is small. Thus, we find that in a standard quantitative model, staggered price-setting, alone, does not generate business cycle fluctuations.
\end{abstract}

KEYWORDS: Staggered price-setting, endogenous price stickiness, monetary business cycles.

\section{INTRODUCTION}

Since the early 1970s, macroeconomists have known how to construct general equilibrium models in which monetary shocks generate contemporaneous output fluctuations. (Examples of such models include the work of Lucas (1972, 1990), Fischer (1977), Phelps and Taylor (1977), and Lucas and Woodford (1993).) The more difficult problem is to construct models in which monetary shocks generate the main feature of business cycles: persistent movements in output. In a large class of models, generating such persistence requires that prices not change much for a long time after monetary shocks. An unappealing way of generating persistence is to simply assume that prices are exogenously fixed for long periods of time. A preferable way is to construct models in which small 
frictions lead to long periods of endogenous price rigidity and, hence, persistent output movements.

Staggered price-setting provides a promising mechanism to generate long periods of endogenous price stickiness with the small frictions of short periods of exogenous price stickiness. Taylor (1980, p. 2) provides an eloquent exposition of this mechanism:

Because of the staggering, some firms will have established their wage rates prior to the current negotiations, but others will establish their wage rates in future periods. Hence, when considering relative wages, firms and unions must look both forward and backward in time to see what other workers will be paid during their own contract period. In effect, each contract is written relative to other contracts, and this causes shocks to be passed on from one contract to another - a sort of "contract multiplier."

Thus, the idea is that staggered price-setting leads to interactions among price-setters that generate longer movements in output than does a similar model with synchronized price-setting. Taylor (1980) and Blanchard (1991) investigate this mechanism for generating persistent output fluctuations, but both exogenously specify the rules for setting wages or prices.

Here we study a quantitative general equilibrium model with rational price-setting firms and staggered price-setting and ask if the model can generate a monetary business cycle. In particular, we use a variant of a standard sticky price model in which imperfectly competitive firms set nominal prices and real money balances enter the consumer's utility function. ${ }^{2}$ To this setup we add time, uncertainty, and capital accumulation, as well as staggered price-setting. We ask whether the model with a short period of exogenous price stickiness can generate long periods of endogenous price stickiness and persistent output fluctuations. Our main finding is that it cannot: staggered price-setting, by itself, does not generate business cycles driven by monetary shocks.

We also find that the intertemporal links of capital accumulation and interest-sensitive money demand play a central role in generating the persistence problem. Specifically, we show that in versions of our model without intertemporal links, staggered price-setting leads to persistent output 
fluctuations after monetary shocks, but once such links are introduced, output fluctuations are no longer persistent.

Our model has a continuum of monopolistically competitive firms that produce differentiated products using capital and labor. These firms set nominal prices for a fixed number of periods and do so in a staggered fashion. In particular, each period, $1 / N$ of the firms choose new prices, which are then fixed for $N$ periods. The consumer side of the model is standard. Consumers are infinitely lived and have preferences over consumption, leisure, and real money balances. The nominal money supply follows an exogenous stochastic process.

We measure the effect of staggered price-setting on the persistence of output by the contract multiplier. This multiplier is the ratio of the half-life of output deviations after a monetary shock with staggered price-setting to the corresponding half-life with synchronized price setting. The halflife of output deviations with synchronized price-setting is roughly one-half the length of exogenous price stickiness. The half-life of output in the data is 10 quarters. Thus, if the period of exogenous price stickiness is about one quarter, then the model with staggered price-setting must produce a contract multiplier of about 20 in order to match the data.

Our benchmark specification is the standard one in the business cycle literature. The utility function has unit elasticity of substitution between consumption and leisure and is thus consistent with balanced growth. Our specification of demand for intermediate goods has constant elasticity, as in the work of Dixit and Stiglitz (1977). Our technology has constant returns to scale. When we calibrate the model, we find that the contract multiplier is roughly 1 . Thus, for our benchmark specification, the staggered price-setting mechanism does not generate persistence.

In order to gain some intuition for these results, we see what happens when we eliminate capital and impose a static money demand equation. The linearized version of this model consists of two equations, a static money demand equation and a price-setting equation, that are essentially identical to those used by Taylor (1980). The only difference between Taylor's equations and ours 
(besides his wages being relabeled as our prices) is that in Taylor's formulation the coefficient on the sum of future output in the price-setting equation is a free parameter, while in ours it is a function of the parameters of the underlying economy. For the model to generate a persistent output response to a monetary shock, this coefficient must be small, so that monetary shocks do not induce firms to raise their prices much. In our model, this coefficient is the product of two parameters: the sensitivity of prices to costs and the sensitivity of costs to output. With constant elasticity of demand, prices move one-for-one with costs. With unit elasticity of substitution in preferences, costs are extremely sensitive to output. Thus, in our model, the coefficient on the sum of future output is large, and monetary shocks do not have persistent effects on output.

We examine three ways of possibly increasing the persistence of output movements. One is to make consumption and leisure close to perfect substitutes in preferences, so that costs are less sensitive to output. With such preferences, the contract multiplier is 20 without intertemporal links but less than 1 with such links. Thus, while eliminating the intertemporal links of capital accumulation and interest-sensitive money demand makes developing analytical expressions easy, this procedure can be misleading. We also find that both with and without intertemporal links, prices change hardly at all after a monetary shock, but with intertemporal links, output is not persistent. This finding shows that endogenous price stickiness, by itself, does not necessarily imply persistent output fluctuations.

Another mechanism we explore, suggested by Kimball (1995), is designed to make prices less sensitive to cost changes. If intermediate goods producers face an elasticity of demand which rises as their relative prices rise, so that demand is convex, then these producers may optimally choose not to raise their prices much after a monetary shock that raises output and costs. We show that generating persistence from this feature requires extraordinarily convex demand functions for intermediate goods.

A third potentially helpful mechanism has been suggested by Rotemberg (1996). He suggests 
that persistence can be increased if firms face upward-sloping marginal cost curves, as they do if they use specific factors that are inelastically supplied. Adding specific factors makes costs and prices less sensitive to wage changes. Indeed, with specific factors and with extremely elastic demand, large contract multipliers can be obtained in the model without intertemporal links. But here, too, adding intertemporal links reduces the contract multiplier significantly.

Finally, we consider a model with combinations of all the variations we have explored. We find that the contract multiplier is approximately 2. Thus, to get the kind of persistence seen in the data, the exogenous price stickiness needs to last roughly $2 \frac{1}{2}$ years.

\section{A Benchmark Monetary Economy}

Consider a monetary economy populated by a large number of identical, infinitely lived consumers. In each period $t$, the economy experiences one of finitely many events $s_{t}$. We denote by $s^{t}=\left(s_{0}, \ldots, s_{t}\right)$ the history of events up through and including period $t$. The probability, as of period 0 , of any particular history $s^{t}$ is $\pi\left(s^{t}\right)$. The initial realization $s_{0}$ is given.

In each period $t$, the commodities in this economy are labor, a consumption-capital good, money, and a continuum of intermediate goods indexed by $i \in[0,1]$. The technology for producing final goods from intermediate goods at history $s^{t}$ is

$$
y\left(s^{t}\right)=\left[\int y\left(i, s^{t}\right)^{\theta} d i\right]^{\frac{1}{\theta}},
$$

where $y\left(s^{t}\right)$ is the final good, $y\left(i, s^{t}\right)$ is an intermediate good of type $i$, and the elasticity of substitution between goods is $1 /(1-\theta)$. The technology for producing each intermediate good $i$ is a standard constant returns to scale production function:

$$
y\left(i, s^{t}\right)=F\left(k\left(i, s^{t}\right), l\left(i, s^{t}\right)\right)
$$

where $k\left(i, s^{t}\right)$ and $l\left(i, s^{t}\right)$ are the inputs of capital and labor.

Final goods producers behave competitively. In each period $t$, they choose inputs $y\left(i, s^{t}\right)$ for 
all $i \in[0,1]$ and output $y\left(s^{t}\right)$ to maximize profits given by

$$
\max \bar{P}\left(s^{t}\right) y\left(s^{t}\right)-\int P\left(i, s^{t-1}\right) y\left(i, s^{t}\right) d i
$$

subject to (1), where $\bar{P}\left(s^{t}\right)$ is the price of the final good in period $t$ and $P\left(i, s^{t-1}\right)$ is the price of intermediate good $i$ in period $t$. The intermediate goods prices do not depend on $s_{t}$ because period $t$ prices in our economy are set before the realization of the period $t$ shocks. Solving the problem in (3) gives the input demand functions:

$$
y^{d}\left(i, s^{t}\right)=\left[\frac{\bar{P}\left(s^{t}\right)}{P\left(i, s^{t-1}\right)}\right]^{\frac{1}{1-\theta}} y\left(s^{t}\right) .
$$

The zero-profit condition implies that

$$
\bar{P}\left(s^{t}\right)=\left[\int P\left(i, s^{t-1}\right)^{\frac{\theta}{\theta-1}} d i\right]^{\frac{\theta-1}{\theta}} .
$$

Notice that in equilibrium the output price in period $t$ depends on only $s^{t-1}$.

Intermediate goods producers behave as imperfect competitors. They set prices for $N$ periods and do so in a staggered fashion. In particular, in each period $t$, a fraction $1 / N$ of these producers choose new prices $P\left(i, s^{t-1}\right)$ before the realization of the event $s_{t}$. These prices are set for $N$ periods, so for this group of intermediate goods producers, $P\left(i, s^{t+\tau-1}\right)=P\left(i, s^{t-1}\right)$ for $\tau=0, \ldots, N-1$. The intermediate goods producers are indexed so that producers indexed $i \in[0,1 / N]$ set new prices in $0, N, 2 N$, and so on, while producers indexed $i \in[1 / N, 2 / N]$ set new prices in $1, N+1,2 N+1$, and so on, for the $N$ cohorts of intermediate goods producers. In period $t$, each producer in a cohort chooses prices $P\left(i, s^{t-1}\right)$ to maximize discounted profits from period $t$ to period $t+N-1$. That is, each solves this problem:

$$
\max _{P\left(i, s^{t-1}\right)} \sum_{\tau=t}^{t+N-1} \sum_{s^{\tau}} Q\left(s^{\tau} \mid s^{t-1}\right)\left[P\left(i, s^{t-1}\right)-v\left(s^{\tau}\right) \bar{P}\left(s^{\tau}\right)\right] y^{d}\left(i, s^{\tau}\right),
$$

where $Q\left(s^{\tau} \mid s^{t-1}\right)$ is the price of one dollar in $s^{\tau}$ in units of dollars at $s^{t-1}, v\left(s^{t}\right)$ is the unit cost of production at $s^{t}$, and $y^{d}\left(i, s^{t}\right)$ is given in (4). The unit cost of production is given by

$$
v\left(s^{t}\right)=\min _{k, l} r\left(s^{t}\right) k+w\left(s^{t}\right) l
$$


subject to $F(k, l) \geq 1$, where $r\left(s^{t}\right)$ is the rental rate on capital and $w\left(s^{t}\right)$ is the real wage rate. The solution to the problem stated in (6) is

$$
P\left(i, s^{t-1}\right)=\frac{\sum_{\tau=t}^{t+N-1} \sum_{s^{\tau}} Q\left(s^{\tau} \mid s^{t-1}\right) \bar{P}\left(s^{\tau}\right)^{\frac{2-\theta}{1-\theta}} v\left(s^{\tau}\right) y\left(s^{\tau}\right)}{\theta \sum_{\tau=t}^{t+N-1} \sum_{s^{\tau}} Q\left(s^{\tau} \mid s^{t-1}\right) \bar{P}\left(s^{\tau}\right)^{\frac{1}{1-\theta}} y\left(s^{\tau}\right)} .
$$

Implicit in this problem are the demands for capital and labor by the intermediate goods producers. (Note that these factor demands are the unit factor demands, which solve (7), multiplied by the level of output of the intermediate goods producer.) These factor demands, $k\left(i, s^{t}\right)$ and $l\left(i, s^{t}\right)$, of producer $i$ in period $t$ are made after the realization of the event $s_{t}$ and thus depend on $s^{t}$. Cost minimization implies that

$$
\frac{F_{l}\left(k\left(i, s^{t}\right), l\left(i, s^{t}\right)\right)}{F_{k}\left(k\left(i, s^{t}\right), l\left(i, s^{t}\right)\right)}=\frac{w\left(s^{t}\right)}{r\left(s^{t}\right)}
$$

Given constant returns to scale, this implies that capital-labor ratios are equated across the intermediate goods firms, so for all $i \in[0,1]$,

$$
\frac{k\left(i, s^{t}\right)}{l\left(i, s^{t}\right)}=\frac{k\left(0, s^{t}\right)}{l\left(0, s^{t}\right)}
$$

In what follows, each intermediate goods firm has the Cobb-Douglas production function, $F\left(k\left(i, s^{t}\right)\right.$, $\left.l\left(i, s^{t}\right)\right)=k\left(i, s^{t}\right)^{\alpha} l\left(i, s^{t}\right)^{1-\alpha}$, where $\alpha$ is the share of capital in costs. Thus (9) can be written as

$$
\left(\frac{1-\alpha}{\alpha}\right) \frac{k\left(i, s^{t}\right)}{l\left(i, s^{t}\right)}=\frac{w\left(s^{t}\right)}{r\left(s^{t}\right)}
$$

Consumer preferences are given by

$$
\sum_{t=0}^{\infty} \sum_{s^{t}} \beta^{t} \pi\left(s^{t}\right) U\left(c\left(s^{t}\right), l\left(s^{t}\right), M\left(s^{t}\right) / \bar{P}\left(s^{t}\right)\right),
$$

where $0<\beta<1$ is the discount factor and where $c\left(s^{t}\right), l\left(s^{t}\right)$, and $M\left(s^{t}\right)$ are consumption, labor, and nominal money balances, respectively. In each period $t=0,1, \ldots$, consumers choose their period $t$ allocations after the realization of the event $s_{t}$. The problem of consumers is to choose rules for consumption $c\left(s^{t}\right)$, labor $l\left(s^{t}\right)$, capital stocks $k\left(s^{t}\right)$, nominal money balances $M\left(s^{t}\right)$, and 
one-period nominal bonds $B\left(s^{t+1}\right)$ to maximize (12) subject to the sequence of budget constraints

$$
\begin{gathered}
\bar{P}\left(s^{t}\right)\left(c\left(s^{t}\right)+k\left(s^{t}\right)\right)+M\left(s^{t}\right)+\sum_{s_{t+1}} Q\left(s^{t+1} \mid s^{t}\right) B\left(s^{t+1}\right) \\
\leq \bar{P}\left(s^{t}\right)\left(w\left(s^{t}\right) l\left(s^{t}\right)+\left[r\left(s^{t}\right)+1-\delta\right] k\left(s^{t-1}\right)\right) \\
+M\left(s^{t-1}\right)+B\left(s^{t}\right)+\Pi\left(s^{t}\right)+T\left(s^{t}\right)
\end{gathered}
$$$$
(t=0,1, \ldots)
$$

and borrowing constraints $B\left(s^{t+1}\right) \geq \bar{B}$ for some large negative number $\bar{B}$. Here $\Pi\left(s^{t}\right)$ is the nominal profits of the intermediate goods producers, $T\left(s^{t}\right)$ is nominal transfers, and $\delta$ is the depreciation rate of capital. The initial conditions $k\left(s^{-1}\right), M\left(s^{-1}\right)$, and $B\left(s^{0}\right)$ are given. Each of the nominal bonds $B\left(s^{t+1}\right)$ is a claim to one dollar in state $s^{t+1}$ and costs $Q\left(s^{t+1} \mid s^{t}\right)$ dollars in state $s^{t}$. In terms of relating the prices in the intermediate goods producers' problem to these prices, note that $Q\left(s^{\tau} \mid s^{t}\right)=Q\left(s^{t+1} \mid s^{t}\right) Q\left(s^{t+2} \mid s^{t+1}\right) \cdots Q\left(s^{\tau} \mid s^{\tau-1}\right)$ for all $\tau>t$. The first-order conditions for the consumer can be written as

$$
\begin{aligned}
& -\frac{U_{l}\left(s^{t}\right)}{U_{c}\left(s^{t}\right)}=w\left(s^{t}\right), \\
& \frac{U_{c}\left(s^{t}\right)}{\bar{P}\left(s^{t}\right)}-\frac{U_{m}\left(s^{t}\right)}{\bar{P}\left(s^{t}\right)}=\beta \sum_{s_{t+1}} \pi\left(s^{t+1} \mid s^{t}\right) \frac{U_{c}\left(s^{t+1}\right)}{\bar{P}\left(s^{t+1}\right)} \\
& U_{c}\left(s^{t}\right)=\beta \sum_{s_{t+1}} \pi\left(s^{t+1} \mid s^{t}\right) U_{c}\left(s^{t+1}\right)\left[r\left(s^{t+1}\right)+1-\delta\right], \\
& Q\left(s^{\tau} \mid s^{t}\right)=\beta^{\tau-t} \pi\left(s^{\tau} \mid s^{t}\right) \frac{U_{c}\left(s^{\tau}\right)}{U_{c}\left(s^{t}\right)} \frac{\bar{P}\left(s^{t}\right)}{\bar{P}\left(s^{\tau}\right)}
\end{aligned}
$$

for all $\tau>t$, where $U_{c}\left(s^{t}\right), U_{l}\left(s^{t}\right)$, and $U_{m}\left(s^{t}\right)$ denote the derivatives of the utility function with respect to its arguments and $\pi\left(s^{\tau} \mid s^{t}\right)=\pi\left(s^{\tau}\right) / \pi\left(s^{t}\right)$ is the conditional probability of $s^{\tau}$ given $s^{t}$.

The nominal money supply process is given by $M\left(s^{t}\right)=\mu\left(s^{t}\right) M\left(s^{t-1}\right)$, where $\mu\left(s^{t}\right)$ is a stochastic process. New money balances are distributed to consumers in a lump-sum fashion by having nominal transfers satisfy $T\left(s^{t}\right)=M\left(s^{t}\right)-M\left(s^{t-1}\right)$.

In terms of market-clearing conditions, consider first the factor markets. Notice that the 
capital stock chosen by consumers in period $t-1$ for rental in period $t$ is $k\left(s^{t-1}\right)$ while the labor supply in period $t$ is $l\left(s^{t}\right)$. In turn, each intermediate goods producer $i$ chooses factor demands after the realization of uncertainty $s_{t}$ in period $t$, so the demands for capital and labor are $k\left(i, s^{t}\right)$ and $l\left(i, s^{t}\right)$. Factor market-clearing thus requires that

$$
\begin{aligned}
& k\left(s^{t-1}\right)=\int k\left(i, s^{t}\right) d i \\
& l\left(s^{t}\right)=\int l\left(i, s^{t}\right) d i
\end{aligned}
$$

Bond market-clearing requires that $B\left(s^{t+1}\right)=0$. The resource constraint for this economy is

$$
c\left(s^{t}\right)+k\left(s^{t}\right)=y\left(s^{t}\right)+(1-\delta) k\left(s^{t-1}\right) .
$$

An equilibrium for this economy is, then, a collection of allocations for consumers $c\left(s^{t}\right), l\left(s^{t}\right)$, $k\left(s^{t-1}\right), M\left(s^{t}\right), B\left(s^{t+1}\right)$; allocations for intermediate goods producers $k\left(i, s^{t}\right), l\left(i, s^{t}\right)$ for $i \in[0,1]$; allocations for final goods producers $y\left(s^{t}\right)$ and $y\left(i, s^{t}\right)$ for $i \in[0,1]$; together with prices $w\left(s^{t}\right)$, $r\left(s^{t}\right), Q\left(s^{\tau} \mid s^{t}\right)$ for $\tau=t, \ldots, t+N-1, \bar{P}\left(s^{t}\right)$, and $P\left(i, s^{t-1}\right)$ for $i \in[0,1]$ that satisfy the following conditions: (i) taking prices as given, consumer allocations solve the consumer's problem; (ii) taking all prices but his own as given, each intermediate goods producer's price solves (6); (iii) taking the prices as given, the final goods producer's allocations solve the final goods producer's problem; (iv) the factor market conditions (17) and (18) and the resource constraint (19) hold, and the bond market clears.

\section{Computation of Equilibrium}

Now we briefly describe how we compute an equilibrium in the benchmark economy. We begin by substituting out a number of variables and reducing the equilibrium to four equations: the resource constraint, a pricing equation, an Euler equation for money, and an Euler equation for capital. Once we have these four equations, we compute Markov equilibria in which allocations are functions of the state of the economy. The state variables are lagged prices, the capital stock, and 
money shocks. The decision variables are current prices, consumption, labor, and investment. In what follows, we will be focusing on the symmetric equilibrium in which all the intermediate goods producers of the same cohort make identical decisions. Thus, $P\left(i, s^{t}\right)=P\left(j, s^{t}\right), k\left(i, s^{t}\right)=k\left(j, s^{t}\right)$, $l\left(i, s^{t}\right)=l\left(j, s^{t}\right), y\left(i, s^{t}\right)=y\left(j, s^{t}\right)$ for all $i, j \in[0,1 / N]$, and so on, for the $N$ cohorts.

We begin with the resource constraint. Equating supplies of and demands for each intermediate good using equations (2) and (4) and integrating gives

$$
\bar{P}\left(s^{t}\right)^{\frac{1}{1-\theta}}\left(\int P\left(i, s^{t-1}\right)^{\frac{1}{\theta-1}} d i\right) y\left(s^{t}\right)=F\left(k\left(s^{t-1}\right) / l\left(s^{t}\right), 1\right)\left(\int l\left(i, s^{t}\right) d i\right)
$$

where we have exploited the facts that $F$ is a constant returns to scale production function and that capital-labor ratios are equated across producers, as in (10). Simplifying using (18) gives

$$
y\left(s^{t}\right)=F\left(k\left(s^{t-1}\right), l\left(s^{t}\right)\right)\left(\frac{\bar{P}\left(s^{t}\right)^{\frac{1}{\theta-1}}}{\int P\left(i, s^{t-1}\right)^{\frac{1}{\theta-1}} d i}\right) .
$$

Substituting (20) into (19) gives the resource constraint we use in our computations.

We can now develop the pricing equation. We first express unit cost in terms of the aggregate allocations. To do so, we solve the minimization problem in (7) and use (10) and (13) to get

$$
v\left(s^{t}\right)=-\frac{1}{1-\alpha} \frac{U_{l}\left(s^{t}\right)}{U_{c}\left(s^{t}\right)}\left(\frac{l\left(s^{t}\right)}{k\left(s^{t-1}\right)}\right)^{\alpha} .
$$

Since all prices are equal, within each cohort of producers, we need only record one price per cohort and not the index identifying the producers. Thus, from now on, we drop the dependence on $i$, and we let $P\left(s^{t-1}\right)$ denote the prices set at the beginning of period $t, P\left(s^{t-2}\right)$ denote the prices set at the beginning of period $t-1$, and so on. Using (5), we can write the aggregate price level as

$$
\bar{P}\left(s^{t}\right)=\left[\frac{1}{N} P\left(s^{t-1}\right)^{\frac{\theta}{\theta-1}}+\cdots+\frac{1}{N} P\left(s^{t-N}\right)^{\frac{\theta}{\theta-1}}\right]^{\frac{\theta-1}{\theta}} .
$$

Using (16), (20), (21), and (22) in (8), we obtain the pricing equation we use in our computations.

Finally, we rewrite the Euler equations for money and capital, (14) and (15), using (22) to substitute for $\bar{P}\left(s^{t}\right)$ and using (10), (11), and (13) to substitute for $r\left(s^{t}\right)$. 
We are interested in a stationary equilibrium and thus restrict the stochastic processes for the growth of the money supply to be Markov. A stationary equilibrium for this economy consists of stationary decision rules that are functions of the state of the economy. Because producers choose their prices before the current money shock is realized, while other allocations are chosen after the money shock is realized, in each period we must record two states for the economy. The state for producers in period $t$ must record the $N-1$ intermediate goods prices in addition to the capital stock and lagged money growth rates. The state for other allocations in period $t$, such as consumer allocations and input allocations for producers, must record the state for producers plus the current money growth rates. In any period $t, N-1$ prices prevail for intermediate goods, namely, those set at the beginning of period $t-1, P\left(s^{t-2}\right)$; those set at the beginning of period $t-2, P\left(s^{t-3}\right)$; and so on, through those set in period $t-(N-1), P\left(s^{t-N}\right)$. We normalize prices by dividing them by the money stock. Thus, the state for producers is $\left[P\left(s^{t-2}\right) / M\left(s^{t-1}\right), \ldots, P\left(s^{t-N}\right) / M\left(s^{t-1}\right), k\left(s^{t-1}\right)\right.$, $\left.\mu\left(s^{t-1}\right)\right]$. The state for other allocations also includes $\mu\left(s^{t}\right)$. The decision variables for period $t$ are aggregate consumption in $t, c\left(s^{t}\right)$; aggregate labor supply in $t, l\left(s^{t}\right)$; and the normalized price of the cohort of intermediate goods producers that are setting their prices at the beginning of period $t, P\left(s^{t-1}\right) / M\left(s^{t-1}\right)$.

In some of the models we consider, investment is extremely volatile. To reduce that volatility, we introduce adjustment costs in changing the capital stock employed by each intermediate goods producer. Specifically, the law of motion for capital used in producing good $i$ is given by

$$
k\left(i, s^{t}\right)=(1-\delta) k\left(i, s^{t-1}\right)-\phi\left(\frac{x\left(i, s^{t}\right)}{k\left(i, s^{t-1}\right)}\right) k\left(i, s^{t-1}\right)+x\left(i, s^{t}\right),
$$

where $\phi$ is the adjustment cost function and $x$ is investment. The problem of monopolist $i$ who chooses prices at date $t, t+N, t+2 N$ and so on is to choose $P\left(i, s^{\tau}\right), l\left(i, s^{\tau}\right), x\left(i, s^{\tau}\right)$, and $k\left(i, s^{\tau}\right)$ for $\tau \geq t$ to maximize

$$
\sum_{\tau=t}^{\infty} \sum_{s^{\tau}} Q\left(s^{\tau} \mid s^{t-1}\right)\left[P\left(i, s^{\tau}\right) y^{d}\left(i, s^{\tau}\right)-w\left(s^{\tau}\right) \bar{P}\left(s^{\tau}\right) l\left(i, s^{\tau}\right)-\bar{P}\left(s^{\tau}\right) x\left(i, s^{\tau}\right)\right]
$$


subject to (4), (23), $y\left(i, s^{t}\right)=F\left(k\left(i, s^{t-1}\right), l\left(i, s^{t}\right)\right)$, and the constraints $P\left(i, s^{\tau}\right)=P\left(i, s^{t-1}\right)$ for $\tau=t, \ldots, t+N-1, P\left(i, s^{\tau}\right)=P\left(i, s^{t+N-1}\right)$ for $\tau=t+N, \ldots, t+2 N-1$, and so on. Clearly, in computing an equilibrium for this economy, we must record the capital stock employed by the representative producer in each cohort, and we expand the state and decision variables accordingly. We also modify the resource constraint appropriately. We then linearize the resulting equations around the steady state and use standard methods to obtain linear decision rules. When $N=1$ and 2 , we check the accuracy of the linear decision rules against nonlinear decision rules obtained by the finite element method. (See the work of McGrattan (1996).)

\section{Calibration of the Benchmark Economy}

Now we describe how we chose the parameter values for the benchmark economy which are summarized in panel A of Table I. Later, we will conduct a wide range of sensitivity analyses, so we view this calibration as only setting the midpoint of the ranges for each of the parameters. These ranges are set wide enough to encompass most estimates of the various parameters in the literature.

Consider a utility function of the form

$$
U(c, l, M / \bar{P})=\left[\left(\omega c^{\frac{\eta-1}{\eta}}+(1-\omega)(M / \bar{P})^{\frac{\eta-1}{\eta}}\right)^{\frac{\eta}{\eta-1}}(1-l)^{\psi}\right]^{1-\sigma} /(1-\sigma),
$$

where $\omega$ is the share parameter, $\eta$ is interest elasticity, $\psi$ is the weight on leisure, and $\sigma$ is risk aversion. Utility functions of this form are attractive because they are consistent with balanced growth. (See the work of Cooley and Prescott (1995).) But these functions have the unattractive feature that the share of time devoted to the market is linked to the labor supply elasticity, which is given by $(1-l) / l$. In Section 5 , we consider preferences that do not have this feature.

We chose parameter values for the utility function (24) as follows. For $\omega$ and $\eta$, we drew on the money demand literature. Our model can be used to price a variety of assets, including a nominal bond that costs one dollar at $s^{t}$ and pays a gross interest rate of $R\left(s^{t}\right)$ dollars in all states $s^{t+1}$. The first-order condition for this asset can be written as $U_{m}\left(s^{t}\right)=U_{c}\left(s^{t}\right)\left(R\left(s^{t}\right)-1\right) / R\left(s^{t}\right)$. 
Using our specification of utility, we can rewrite the first-order condition as

$$
\log \frac{M\left(s^{t}\right)}{\bar{P}\left(s^{t}\right)}=-\eta \log \frac{\omega}{1-\omega}+\log c\left(s^{t}\right)-\eta \log \left(\frac{R\left(s^{t}\right)-1}{R\left(s^{t}\right)}\right) .
$$

We regressed the log of consumption velocity on the interest rate variable in (25) using several data series from Citibase for 1960:1-1995:4: M1; the GDP deflator; the consumption of services, nondurables, and durables; and the three-month U.S. Treasury bill rate. The implied value of $\omega$ from our regression is 0.94 . Our estimate of the interest elasticity is $\eta=0.39$, with a standard error of 0.033. This elasticity is similar to that estimated by Mankiw and Summers (1986) and Lucas (1988) and smaller than that of Stock and Watson (1993).

Based on the work of Basu and Fernald (1994, 1995), Basu and Kimball (1997), and Basu (1996), we chose $\theta=0.9$, which implies a markup of 11 percent and an elasticity of demand of 10 .

We set the parameters $\beta, \delta, \psi$, and $\alpha$ using balanced growth path relationships in our model and various statistics in the data. (Again, the parameter values are given in Table I.) With these parameters, our model predicts an annualized capital-output ratio of 2.65 , an investment-output ratio of 0.23 , and a share of time allocated to the market of $1 / 3$. The capital-output ratio and the investment-output ratio are the same as those calculated by Christiano (1988), and the time allocated to the market is similar to that of Cooley and Prescott (1995). In using the national income accounts to determine the capital share in our model, we assumed that monopoly profits are allocated proportionately to capital and labor. With this assumption, the capital share of income in our model is $1 / 3$, which is similar to that estimated by Christiano (1988).

We chose an adjustment cost function of the form $\phi(x / k)=b[(x / k)-\delta]^{2} / 2$, where $b \geq 0$. We set the adjustment cost parameter $b$ so that the Hodrick-Prescott-filtered data from the model produce a standard deviation of investment relative to that of output similar to the corresponding statistic for the U.S. economy (3.25). We set $b=0$ when the relative volatility of investment in the economy with no adjustment costs is too small.

The stochastic process for the growth rate of the money stock is given by $\log \mu_{t}=\rho \log \mu_{t-1}+$ 
$\epsilon_{t}$, where $\epsilon$ is an independent and identically normally distributed mean-zero shock. The serial correlation parameter for money growth rates, $\rho$, was calculated using Citibase's quarterly data on M1 from 1959:3 through 1995:2. We obtained $\rho=0.57$.

In our experiments, we will vary the amount of staggering, $N$, as well as the length of time of exogenous price stickiness, which we denote by $T$. When we vary these, we also adjust the discount factor $\beta$, the depreciation rate $\delta$, and the serial correlation parameter $\rho$ so as to keep the capitaloutput and investment-output ratios and the quarterly serial correlation unchanged. Specifically, we set $\beta=0.97^{\frac{T}{N}}, \delta=1-0.92^{\frac{T}{N}}$, and $\rho=0.57^{\frac{4 T}{N}}$, where $T$ is measured in years. For most of the experiments, we set $T$ equal to one-quarter of one year and $N=13$, so that prices are fixed for one quarter at a time, a cohort of producers chooses prices every week, and consumers make their decisions weekly.

Our notion of a contract multiplier is designed to measure how much staggered price-setting increases the persistence of output relative to synchronized price-setting. We measure the persistence of output by its half-life, defined as the length of time after a shock before the deviation in output shrinks to half of its impact value. With synchronized price-setting, on average the half-life of output is one-half the length of exogenous stickiness. The reason is that monetary shocks occur randomly between price adjustments, and the associated movements in output last only until the next price adjustment. Thus, we define the contract multiplier in a model with staggered pricesetting as the ratio of the half-life of output to one-half the length of exogenous stickiness. Hence, a multiplier of, say, 5 means that staggered price-setting generates output movements that last 5 times longer than they would with synchronized price-setting. An attractive feature of the contract multiplier is that in our quantitative models, this multiplier is approximately invariant to the length of exogenous price stickiness.

We measured the half-life of output in the data by fitting an ARMA process to the logarithm 
of real GDP, after removing a quadratic trend. The fitted equation is

$$
\log y_{t}=\underset{(0.066)}{1.30 \log y_{t-1}-}-\underset{(0.066)}{0.38 \log y_{t-2}+\epsilon_{t}}
$$

where the numbers in parentheses are standard errors. The Ljung-Box $Q$ test indicates little evidence for serial correlation of the residuals $(Q=13.8$ with significance level 0.46$)$. From this equation, we calculated the half-life of output to be 10 quarters, or $2 \frac{1}{2}$ years. This measure is admittedly imperfect, but provides a useful benchmark.

For the bulk of our analysis, we consider economies with a period of exogenous price stickiness of 1 quarter. The contract multiplier needed to match this measure of persistence is 20 . With one month of exogenous price stickiness, the needed contract multiplier is 60 ; with one year, 5 .

\section{Results for the Benchmark Economy}

The main question we address here is whether staggered price-setting can lead to persistent movements in output. We begin by considering a stripped-down version of the benchmark model that we can solve analytically for the equilibrium. In this version, we abstract from capital and impose a static money demand equation. We show that in order to get persistence, the equilibrium wage rate must change little when consumption changes. We show that for the class of preferences in our benchmark model, the equilibrium wage changes so much that we cannot get persistence.

Consider a version of the benchmark model without capital $(\alpha=0)$ and with two cohorts of monopolists staggering their price-setting $(N=2)$. Suppose that the utility function is given by equation (24), as in the benchmark economy. We log-linearize the equilibrium conditions around a deterministic steady state with a constant money supply. Let $\hat{x}_{i t}, \hat{x}_{t}, \hat{p}_{t}, \hat{w}_{t}, \hat{c}_{t}, \hat{y}_{t}$, and $\hat{m}_{t}$ represent the logarithmic deviations from a steady state for $P\left(i, s^{t-1}\right), P\left(s^{t-1}\right), \bar{P}\left(s^{t}\right), w\left(s^{t}\right), c\left(s^{t}\right), y\left(s^{t}\right)$, and $M\left(s^{t}\right)$, respectively.

Now, simply impose a static money demand equation in which consumption equals real 
balances, so $M\left(s^{t}\right) / \bar{P}\left(s^{t}\right)=c\left(s^{t}\right)=y\left(s^{t}\right)$ and hence

$$
\hat{m}_{t}-\hat{p}_{t}=\hat{y}_{t} .
$$

Next, consider the pricing equation (8). Substituting for $Q$ from equation (16), setting $\beta=1$, and linearizing the resulting equation around the deterministic steady state gives

$$
\hat{x}_{i t}=\frac{1}{2} E_{t-1} \hat{p}_{t}+\frac{1}{2} E_{t-1} \hat{p}_{t+1}+\frac{1}{2} E_{t-1}\left(\hat{w}_{t}+\hat{w}_{t+1}\right)
$$

where $E_{t-1}$ denotes the expectation as of period $t-1$. The price level $\hat{p}_{t}$ is a weighted average of the individual prices:

$$
\hat{p}_{t}=\frac{\hat{x}_{t}}{2}+\frac{\hat{x}_{t-1}}{2} .
$$

Substituting (28) into (27) and imposing equilibrium gives

$$
\hat{x}_{t}=\frac{1}{2} \hat{x}_{t-1}+\frac{1}{2} E_{t-1} \hat{x}_{t+1}+E_{t-1}\left(\hat{w}_{t}+\hat{w}_{t+1}\right) .
$$

Next, note that with $\alpha=0$ and $N=2$, using (22), (20) can be written as

$$
y\left(s^{t}\right)=l\left(s^{t}\right)\left[\frac{1}{2} P\left(s^{t-1}\right)^{\frac{\theta}{\theta-1}}+\frac{1}{2} P\left(s^{t-2}\right)^{\frac{\theta}{\theta-1}}\right]^{\frac{1}{\theta}}\left[\frac{1}{2} P\left(s^{t-1}\right)^{\frac{1}{\theta-1}}+\frac{1}{2} P\left(s^{t-2}\right)^{\frac{1}{\theta-1}}\right]^{-1} .
$$

Log-linearizing this equation around a deterministic steady state gives

$$
\hat{y}_{t}=\hat{l}_{t}
$$

Log-linearizing the labor supply equation (13) around the deterministic steady state gives

$$
\hat{w}_{t}=\frac{\partial \log \left(-\left.\frac{U_{l}}{U_{c}}\right|_{s s}\right)}{\partial \log c} \hat{c}_{t}+\frac{\partial \log \left(-\left.\frac{U_{l}}{U_{c}}\right|_{s s}\right)}{\partial \log M / \bar{P}}\left(\hat{m}_{t}-\hat{p}_{t}\right)+\frac{\partial \log \left(-\left.\frac{U_{l}}{U_{c}}\right|_{s s}\right)}{\partial \log l} \hat{l}_{t},
$$

where the subscript $s s$ denotes that the derivatives are evaluated at the steady state allocations.

With our functional forms (31) becomes

$$
\hat{w}_{t}=\left[\omega\left(\frac{\eta-1}{\eta}\right)+\frac{1}{\eta}\right] \hat{c}_{t}+\left[(1-\omega)\left(\frac{\eta-1}{\eta}\right)\right]\left(\hat{m}_{t}-\hat{p}_{t}\right)+\frac{\theta \omega}{\psi} \hat{l}_{t},
$$


where we have used the facts that the steady state allocations satisfy $c_{s s}=l_{s s}=(M / \bar{P})_{s s}$ and

$$
-\left.\frac{U_{l}}{U_{c}}\right|_{s s}=\frac{\psi}{\omega} \frac{c_{s s}}{\left(1-c_{s s}\right)}=w_{s s}=\theta .
$$

Substituting (26), (30), and $\hat{c}_{t}=\hat{y}_{t}$ in (32) gives the following log-linearized labor supply equation

$$
\hat{w}_{t}=\gamma \hat{y}_{t}
$$

where

$$
\gamma=1+\frac{\theta \omega}{\psi}
$$

Here $\gamma$ is the elasticity of the equilibrium real wage rate with respect to consumption. Substituting (33) into (29) gives

$$
\hat{x}_{t}=\frac{1}{2} \hat{x}_{t-1}+\frac{1}{2} E_{t-1} \hat{x}_{t+1}+\gamma E_{t-1}\left(\hat{y}_{t}+\hat{y}_{t+1}\right)
$$

The system of equations (26), (28), and (35) is the same as that in Taylor (1980). The only difference between our price-setting equation and Taylor's is that our value of $\gamma$ depends on the underlying preferences and technology while Taylor's $\gamma$ is a structural parameter.

The system of equations (26), (28), and (35) can be solved to determine how money shocks are divided into movements in prices and movements in output. Equation (26) implies that large movements in output require small movements in the price level. But equation (35) implies that large movements in output have small effects on the price level only if $\gamma$ is small.

To see how $\gamma$ influences the division of money shocks into price and output movements, we solve the model for $\hat{x}_{t}, \hat{p}_{t}$, and $\hat{y}_{t}$. Substituting for $\hat{y}_{t}$ in (35) using (26) and (28), we obtain

$$
E_{t-1} \hat{x}_{t+1}-2 \frac{1+\gamma}{1-\gamma} \hat{x}_{t}+\hat{x}_{t-1}=-\frac{2 \gamma}{1-\gamma} E_{t-1}\left(\hat{m}_{t}+\hat{m}_{t+1}\right)
$$

We can use standard methods to write $\hat{x}_{t}$ as

$$
\hat{x}_{t}=a \hat{x}_{t-1}+\frac{2 a \gamma}{1-\gamma} E_{t-1} \sum_{i=0}^{\infty} a^{i}\left(\hat{m}_{t+i}+\hat{m}_{t+1+i}\right),
$$


where $a$ is the root with absolute value less than 1 which solves $a^{2}-\lambda a+1=0$, where $\lambda=$ $2(1+\gamma) /(1-\gamma)$. This root is equal to

$$
a=\frac{1-\sqrt{\gamma}}{1+\sqrt{\gamma}} .
$$

Now suppose that $\hat{m}_{t}$ is a random walk. After simplifying (36), we can write

$$
\hat{x}_{t}=a \hat{x}_{t-1}+(1-a) \hat{m}_{t-1} .
$$

Using (28) to substitute for $\hat{x}_{t}$ in (38), we obtain

$$
\hat{p}_{t}=a \hat{p}_{t-1}+(1-a)\left(\hat{m}_{t-1}+\hat{m}_{t-2}\right) / 2 \text {. }
$$

Finally, using (26) to substitute for $\hat{p}_{t}$ in (39), we obtain

$$
\hat{y}_{t}=a \hat{y}_{t-1}+\left(\hat{m}_{t}-\hat{m}_{t-1}\right)+(1-a)\left(\hat{m}_{t-1}-\hat{m}_{t-2}\right) / 2 \text {. }
$$

As should be clear from (40), the persistence properties of output with respect to money shocks depend critically on the value of $a$ and, therefore, on the value of $\gamma$. Recall from (34) that $\gamma>1$. Hence it follows from (37) that $a<0$, so output is not persistent.

When $\gamma$ is treated as a free parameter, Taylor's model described by (26), (28), and (35) can produce the needed contract multiplier. When $N=2$, one-half of the length of exogenous price stickiness is 1 . Thus, in order to get a multiplier of 20 , we need a half-life of 20 . If $a>0$, it is easy to show that the half-life of output is given by $t=1-\log (1+a) / \log a$. For a multiplier of 20 , we need $a=0.965$ and hence $\gamma=0.00031$. In our model, $\gamma$ is not a free parameter and is necessarily greater than 1.

In Table II we report values of the contract multiplier for a variety of economies that use our calibrated parameters, except where noted. ${ }^{3}$ We investigate how the intertemporal links of interest sensitive money demand and capital accumulation affect the contract multiplier separately and jointly. The first column of the table refers to economies without capital and with interestinsensitive money demand, while the next three columns refer to economies with only interestsensitive money demand, with only capital, and with both interest-sensitive money demand and 
capital, respectively. We report multipliers for economies with 2 cohorts and i.i.d. money growth since these are comparable to results for the stripped-down version of our model. We also report multipliers for economies with 13 cohorts and serially correlated money growth and think of these multipliers as more relevant for comparing with data.

In Table II we see that for all versions of our benchmark model, the contract multiplier is roughly 1 . With this contract multiplier, in order to generate the half-life of output seen in the data, the exogenous length of price stickiness would have to be 5 years.

Taylor (1980) and Blanchard (1991) conjecture that, if the length of time that prices are fixed is held constant, then increasing the amount of staggering increases the persistence of output fluctuations. We investigate this conjecture by considering versions of our benchmark economy with $N=2,13$, and 26 . The resulting multipliers are $1.06,0.99$, and 0.87 . These results show that increasing the amount of staggering does not increase the persistence of output responses.

We also examine whether the contract multiplier varies with the length of exogenous price stickiness, and we find that it does not. For example, for our benchmark economy, changing the length of price stickiness from one quarter to one year does not change the contract multiplier.

\section{Robustness}

In our benchmark economy, the contract multiplier is extremely small because prices are extremely sensitive to movements in marginal costs. These results suggest that to generate a large contract multiplier, we must find some mechanism that makes prices insensitive to movements in marginal costs. We consider three such mechanisms in what follows. Then, we examine how the contract multiplier changes in the various models as we vary parameters, and we explore how combining the various mechanisms changes the multiplier.

\subsection{Near-Perfect Substitute Preferences}

First, we consider a specification of preferences in which consumption and leisure are nearperfect substitutes. With these preferences, $\gamma$ is small, so that prices are insensitive to movements in 
marginal costs. Intuition suggests that these preferences should generate a large contract multiplier. We find that without the intertemporal links of capital accumulation and interest-sensitive money demand, they do. Once we add intertemporal links, however, the contract multiplier is small.

To see how the substitutability of consumption and leisure is related to $\gamma$, consider the following measure. Let $\eta_{e}$ denote the equilibrium elasticity of substitution between leisure and consumption in a steady state with $c_{s s}=l_{s s}=(M / \bar{P})_{s s}$ defined by

$$
\eta_{e}=-\frac{\partial \log \left(\left.\frac{1-l}{c}\right|_{s s}\right)}{\partial \log \left(-\left.\frac{U_{l}}{U_{c}}\right|_{s s}\right)}
$$

This elasticity measures the percentage change in the equilibrium ratio of leisure to consumption induced by a percentage change in the equilibrium wage rate. In equilibrium, the wage rate equals the marginal rate of substitution between leisure and consumption, consumption equals labor input, and, with static money demand, $c=M / \bar{P}$. It is straightforward to show that $\eta_{e}=1 /[\gamma(1-c)]$. Clearly, for $\gamma$ to be small, $\eta_{e}$ must be large.

This argument leads us to consider utility functions of the form:

$$
U(c, l, M / \bar{P})=\left[\frac{c^{1-\kappa}}{1-\kappa}-\omega_{1} \frac{l^{1+\xi}}{1+\xi}+\omega_{2} \frac{(M / \bar{P})^{1-\nu}}{1-\nu}\right]^{1-\sigma} /(1-\sigma) .
$$

For such utility functions, if $\kappa$ and $\xi$ are small, so that the utility function is close to linear in both consumption and leisure, then $\eta_{e}$ is large. Log-linearizing the labor supply equation (13) gives $\gamma=\kappa+\xi$, where $1 / \xi$ is the labor supply elasticity evaluated at the steady state. With these preferences, we can get a large contract multiplier as long as $\kappa$ and $\xi$ are small enough. For example, a $\kappa$ of 0.0002 and a labor supply elasticity of 9,091 yield $\gamma=0.00031$ and a contract multiplier of 20. These calculations suggest that preferences with high substitutability between consumption and leisure offer one route to persistence. (Blanchard and Fischer (1989) and Blanchard (1990) point to the importance of high labor supply elasticities in generating persistence. Our calculations suggest that near quasi-linearity in consumption is also crucial.) 
To set the parameter $\nu$, we use the money demand equation for this economy:

$$
\log \frac{M}{\bar{P}}=\text { constant }+\frac{\kappa}{\nu} \log c-\frac{1}{\nu} \log \frac{R-1}{R}
$$

where $R$ is the gross nominal interest rate. This money demand equation makes clear that once $\kappa$ is given, we cannot vary the interest elasticity of money demand without also varying the elasticity of consumption. Therefore, when we eliminate the intertemporal link of interest-sensitive money demand, we replace the money demand equation with a static money demand equation of the form $M / \bar{P}=c$. When we allow intertemporal links, we set $\kappa=\nu$, so that the consumption elasticity of money demand is 1 (as balanced growth dictates).

The results for this model show that intertemporal links can have a dramatic effect on the contract multiplier. (See Table II.) With $N=2$, no persistence in money growth, and no intertemporal links, the multiplier is 21.97. The same economy with intertemporal links has a multiplier of only 0.50. The results also show that the key intertemporal link that affects the multiplier is capital accumulation. For the economy with $N=13$ and persistent money growth, the reduction in the multiplier is even more dramatic. Eliminating intertemporal links makes developing analytical solutions easy; that step is, therefore, usually thought of as a useful shortcut. The results here show that this shortcut can be misleading.

For this economy, the impulse responses following a one-time money shock are as follows. Output and consumption rise by a large amount in the impact period and by a much smaller amount thereafter. The contract multiplier is small because money shocks lead to an investment boom in the impact period, which raises the demand for labor and, therefore, wage rates. Since utility is nearly linear in both consumption and labor, the rise in wage rates leads to a large increase in both consumption and labor in the impact period relative to future periods. This makes both the half-life of output and the multiplier small.

Adding adjustment costs would increase the contract multiplier, but would also raise problems. With $N=13$, persistent money growth, and both intertemporal links, the volatility of 
investment relative to output is 0.42 , which is substantially less than the corresponding statistic in the data. Adding adjustment costs to investment will decrease this relative volatility even further, making this a poorer business cycle model along this important dimension. Experiments with a large range of adjustment costs do not change the multiplier much: they reduce the size of the output response in the impact period but also in subsequent periods.

The results for this model also emphasize the role of interest-elastic money demand. In models with a static money demand equation of the form $\hat{m}-\hat{p}=\hat{y}$, the contract multiplier clearly is large if and only if the price level responds slowly over time. In our near-perfect substitutes model, money demand is interest elastic. It turns out that although the price level responds slowly, output is not affected very much, and the contract multiplier is tiny. The reason is that interest rates fall enough so that households willingly demand higher real balances, even though output has not risen much.

One problem with extreme substitutability between consumption and leisure is that these preferences have troublesome implications for the behavior of labor supply with even modest growth in wage rates and consumption. Suppose, for example, that wage rates and consumption grow 2 percent per year. Then, with our parameter values, labor input rises 57 percent each day.

\subsection{Convex Demand}

Now we explore an avenue suggested by Kimball (1995), designed to make prices less sensitive to marginal costs, which should tend to increase the size of the multiplier. To motivate Kimball's idea, note that the log-linearized pricing equation (29) implies that a 1 percent increase in marginal costs (which are simply wage rates in our model without capital) results in a 1 percent increase in prices set by the current cohort of intermediate goods producers. The intuition for this feature is as follows. In static models, a monopolist's markup of price over marginal cost is a simple function of the elasticity of demand. With constant elasticity of demand, the markup is constant, so that when costs rise 1 percent, so do prices. 
Kimball (1995) suggests an alternative formulation of the final goods production technology that results in demand functions with the following feature: as prices rise, the elasticity of demand increases, so that the demand curve is convex. Demand functions of this kind can make the markup decline as prices rise, thus implying that a 1 percent increase in marginal costs results in a less than 1 percent increase in prices. Thus, after a monetary shock, each cohort of firms does not raise prices much, so that output deviates from its steady state for a long time.

We begin by analyzing this alternative formulation in a version of our model without capital and with $N=2$. This alternative formulation closely follows Kimball's (1995) work. Let the technology for producing final goods be implicitly defined by $\int g\left(y_{i} / y\right) d i=1$, where $y_{i}$ is the use of the intermediate good $i$ and $y$ is the output of the final good. Profit maximization by final goods producers, together with zero profits, implies that $P_{i} / \bar{P}=g^{\prime}\left(y_{i} / y\right) / \int g^{\prime}\left(y_{i} / y\right)\left(y_{i} / y\right) d i$. This condition can be inverted to yield the demand function confronting each intermediate goods producer: $y_{i}^{d} / y=d\left(\left(P_{i} / \bar{P}\right) \int g^{\prime}\left(y_{i} / y\right)\left(y_{i} / y\right) d i\right)$, where $d \equiv\left(g^{\prime}\right)^{-1}$. Substituting this demand function into the maximization problem (6), we can solve for the optimal price for intermediate goods producer $i$. Log-linearizing the resulting optimal pricing equation yields

$$
\hat{x}_{i t}=\frac{1}{2} E_{t-1} \hat{p}_{t}+\frac{1}{2} E_{t-1} \hat{p}_{t+1}+\frac{\varphi}{2} E_{t-1}\left(\hat{w}_{t}+\hat{w}_{t+1}\right),
$$

where again prices are written in log-deviation form. The parameter $\varphi$ is given by

$$
\varphi=\frac{1-(1 / \varepsilon)}{2-(\chi / \varepsilon)}
$$

where $\varepsilon$ is the elasticity of demand evaluated at the steady state (that is, $\varepsilon=-d^{\prime}\left(g^{\prime}(1)\right) g^{\prime}(1)$ ) and $\chi$ is the parameter governing the curvature of the demand function (that is, $\chi=$ $\left.-d^{\prime \prime}\left(g^{\prime}(1)\right) g^{\prime}(1) / d^{\prime}\left(g^{\prime}(1)\right)\right)$. Substituting $\hat{w}_{t}=[1+\theta \omega / \psi] \hat{y}_{t}$ and (28) into (43), we obtain

$$
\hat{x}_{t}=\frac{1}{2} \hat{x}_{t-1}+\frac{1}{2} E_{t-1} \hat{x}_{t+1}+\gamma E_{t-1}\left(\hat{y}_{t}+\hat{y}_{t+1}\right)
$$

where $\gamma=\varphi[1+\theta \omega / \psi]$. Note that (45) has the same form as (35) but a different value for $\gamma$. The analysis above demonstrates that lower values of $\gamma$ lead to more persistent output movements. The 
parameter $\varphi$ is determined by the values of $\varepsilon$ and $\chi$. From equation (44), we can see that if the demand function is sufficiently convex, so that $\chi$ is sufficiently negative, then $\varphi$, and hence $\gamma$, can be made arbitrarily small and output can be made arbitrarily persistent. Note also that increases in $\varepsilon$, with $\chi$ held fixed, reduce $\varphi$. We show later that this relation is important.

The key question now is, What values of $\chi$ imply substantial persistence of output? Kimball (1995) chooses a parameterization in which a 1 percent increase in market share, $y_{i} / y$, leads to a decline in the elasticity of demand from 11 to 8 . In our model, the elasticity of demand in the steady state is 10 , so we choose a parameterization in which a 1 percent increase in market share, $y_{i} / y$, leads to a decline in the elasticity of demand from 10 to 7 . We use a Taylor series expansion of the elasticity of demand around the steady state to calculate the value of the curvature parameter associated with Kimball's parameterization. The elasticity of demand is given by $\varepsilon\left(y_{i} / y\right)=-d^{\prime}\left(g^{\prime}\left(y_{i} / y\right)\right) g^{\prime}\left(\left(y_{i} / y\right) /\left(y_{i} / y\right)\right)$. Since $g^{\prime \prime}=1 / d^{\prime}$, we can see that the Taylor series expansion of $\varepsilon\left(y_{i} / y\right)$ around $y_{i} / y=1$ is given by $\varepsilon\left(y_{i} / y\right) \cong \varepsilon(1)-[1+\varepsilon(1)-\chi]\left(y_{i} / y-1\right)$. Using Kimball's parameterization, we obtain a value of $\chi=-289$. This value implies that $\varphi=0.029$, and with our other parameters, the resulting value of $\gamma$ is 0.045 . This value implies a contract multiplier of 2.2 .

Unfortunately, however, this parameterization implies that the demand function must be extraordinarily convex. To appreciate how convex this demand function must be, consider a secondorder Taylor series expansion of the demand function at the steady state, given by

$$
d\left(\frac{P_{i}}{\bar{P}} g^{\prime}(1)\right) \cong 1-\varepsilon(1)\left(\frac{P_{i}}{\bar{P}}-1\right)+\frac{\varepsilon(1) \chi}{2}\left(\frac{P_{i}}{\bar{P}}-1\right)^{2}
$$

Using the parameterization that gives a multiplier of 2.2 , we see that this demand function implies that a 2 percent increase in relative prices results in a 78 percent reduction in demand, and a 2.3 percent increase in relative prices results in zero demand. A demand function with this extreme level of convexity is clearly inconsistent with both casual empiricism and a wide variety of demand studies for a wide range of products. 
The contract multiplier is smaller in the presence of intertemporal links. (See Table II.) When $N=13$ and money growth is persistent, the multiplier is 3.79 without intertemporal links and only 1.55 with such links. The intuition for these results is similar to that in the near-perfect substitutes model.

\subsection{Specific Factors}

Now we assume that each intermediate good is produced using a specific factor in addition to labor and capital. Each of these specific factors is inelastically supplied. The motivation for including these specificities is, of course, to see if they lead to greater persistence in output. As our discussion of the benchmark model makes clear, a key factor determining persistence in models without intertemporal links is the sensitivity of the monopolist's price to changes in economy-wide output. With specific factors, this sensitivity is affected by two forces - the output effect and the wage effect. Increases in economy-wide output induce increases in the monopolist's output and raise the monopolist's costs because of decreasing returns to scale. This increase in costs induces the monopolist to raise the price. Alone, the output effect makes prices more sensitive to changes in output. Increases in wage rates induce a smaller increase in the monopolist's price with decreasing returns to scale. Alone, the wage effect makes prices less sensitive to changes in output. The wage effect is stronger the more elastic is demand. When demand is sufficiently elastic, the wage effect dominates, the monopolist's price is relatively insensitive to aggregate output, and monetary shocks have more persistent effects.

We begin by analyzing a version of this model without intertemporal links. The production function for producing intermediate goods is given by $y\left(i, s^{t}\right)=l\left(i, s^{t}\right)^{1-\alpha}$. One interpretation of this production function is that it is a constant returns to scale production function in labor and a specific factor, such as land. The price-setting equation for the monopolist is given by the analog of $(27)$ :

$$
\hat{x}_{i t}=\frac{1}{2} E_{t-1} \hat{p}_{t}+\frac{1}{2} E_{t-1} \hat{p}_{t+1}+\frac{1}{2} \frac{E_{t-1}\left(\hat{w}_{t}+\hat{w}_{t+1}\right)}{1+A \varepsilon}+\frac{A}{2} \frac{E_{t-1}\left(\hat{y}_{t}+\hat{y}_{t+1}\right)}{1+A \varepsilon},
$$


where $A=\alpha /(1-\alpha)$ and $\varepsilon=1 /(1-\theta)$, which is the elasticity of demand. Comparing (47) to (27), we see that with decreasing returns to scale, two changes have occurred. Relative to (27), (47) has an extra term. This extra term, the last one in (47), is the output effect discussed above and reflects the increase in marginal costs associated with an increase in output. The response of the price to the wage rate is reduced by $1 /(1+A \varepsilon)$ and is the wage effect discussed above. With constant returns to scale $(A=0)$, this price-setting equation does not depend on the elasticity of demand or directly on aggregate output. With decreasing returns to scale, the larger is the demand elasticity, the less sensitive is the best response to wage rates and economy-wide output. Substituting $\hat{w}_{t}=[1+\theta \omega / \psi] \hat{y}_{t}$ and (28) into (47) and imposing equilibrium gives an equation of the form in $(35)$ with

(48) $\gamma=\frac{1+\theta \omega / \psi+A}{1+A \varepsilon}$.

For the parameters given in Table I-namely, $\theta=0.9, \varepsilon=10, \psi=1.5$, and $\omega=0.94$-and with $A=3 / 2$, we get $\gamma=0.19$. This value of $\gamma$ yields a contract multiplier of only 1.35. If, however, the elasticity of demand is large enough, then $\gamma$ can be made arbitrarily close to 0 and the contract multiplier can be made arbitrarily large. For example, we can generate a contract multiplier of 20 with an elasticity of demand of $\varepsilon=6500(\theta=0.9998)$.

While high enough demand elasticities can lead to substantial persistence, they also lead to extremely counterfactual implications regarding the distribution of output across firms in our economy. To see this, note that relative outputs of monopolists $i$ and $j$ are given by $y\left(i, s^{t}\right) / y\left(j, s^{t}\right)=$ $\left[P\left(j, s^{t}\right) / P\left(i, s^{t}\right)\right]^{\varepsilon}$. For example, with $\varepsilon=6500$, a 1 percent difference in relative prices implies a difference in relative outputs equal to $1.2 \times 10^{30}$ percent $\left(1.01^{6500}\right)$.

Introducing intertemporal links into this model also reduces the size of the contract multiplier. Assume that the technology for producing each intermediate good $i$ is given by $F\left(k\left(i, s^{t}\right), l\left(i, s^{t}\right)\right)$ $=k\left(i, s^{t}\right)^{\alpha_{1}} l\left(i, s^{t}\right)^{\alpha_{2}}$, where $\alpha_{1}+\alpha_{2}<1$. The results in Table II show how the multiplier changes once we include capital and interest-sensitive money demand. For the specific factors economy, we 
set $\alpha_{2}=4 / 9$, and when capital is included, we set $\alpha_{1}=2 / 9$. We also assume that adjustment costs to capital are set so that the relative volatility of investment to output is similar to that in the data. Without capital or interest-sensitive money demand links, the multiplier is 1.82 with $N=13$ and $\rho=0.57^{\frac{1}{13}}$. Introducing capital and interest-sensitive money demand reduces this multiplier to 1.33 , which is not much higher than the multiplier's value in our benchmark economy.

\subsection{Sensitivity Analysis}

Finally, we examine how the contract multiplier changes in the various models as we vary parameters, both one at a time and simultaneously. We also consider how combining the various models we have explored changes the multiplier. Here we focus on key parameters. (In Chari, Kehoe, and McGrattan (1998), we report on how the multiplier varies with all of the parameters.) We find that the value of the multiplier is roughly 2 and that combining the various models does not raise the multiplier much.

We begin with the benchmark economy. In Figure 1 we show how the multiplier varies as we vary one parameter at a time for that economy, holding fixed the relative volatility of investment to output. The other parameters for this economy, with the exception of the adjustment cost parameter, are set at their calibrated values given in Table I. In Figure 1, panels A and B illustrate the roles of the intertemporal links. Panel A shows that the multiplier is roughly constant in the interest elasticity of money demand and that the multiplier rises only when the interest elasticity is less than 0.05. Panel B shows that the multiplier does not change much as the capital share varies.

Panel $\mathrm{C}$ in Figure 1 shows that making the utility function more concave than log (increasing the risk aversion parameter $\sigma$ above 1) reduces the multiplier. The contract multiplier varies with the risk aversion parameter because in all our experiments we chose the adjustment cost parameter to produce the volatility of investment relative to output in the data. As the utility function gets more concave, the volatility of investment falls without adjustment costs. To keep the volatility of investment constant, we must reduce adjustment costs as we raise risk aversion. But lowering 
adjustment costs reduces the contract multiplier. When the risk aversion parameter is above 2.2, adjustment costs are not needed and the contract multiplier is small.

Panel D in Figure 1 illustrates that the contract multiplier increases as the demand elasticity $\varepsilon(=1 /(1-\theta))$ increases. The intuition for this finding is similar to that in the specific factors economy. Since capital does not move much, it acts like a factor in fixed supply.

We also experiment by varying some key parameters simultaneously within the ranges reported in Table III. We set the discount factor $\beta$, the depreciation rate $\delta$, and the share parameter in utility $\omega$ at their calibrated values. (See Table I.) Our ranges for the interest elasticity $\eta$, the capital share $\alpha$, risk aversion $\sigma$, and the weight on leisure $\psi$ are chosen to include most of the estimates provided in the literature. We choose $\rho$ so that money growth ranges from independent and identically distributed to very persistent. We choose the elasticity of demand $\varepsilon$ to range from fairly inelastic to an upper bound dictated by computational feasibility. Within these parameter ranges, the largest value of the multiplier we find is 3.05. This occurs with an interest elasticity of 0.2 , a capital share of 0.22 , a weight of 9 on leisure in utility, risk aversion of 1 (that is, log utility), a demand elasticity of 300 , and a serial correlation of 0.96 on money growth.

In panel $\mathrm{A}$ of Figure 2, we show how the multiplier varies as we vary the demand curvature parameter $\chi$ for the convex demand economy, holding fixed the relative volatility of investment. The other parameters for this economy, with the exception of the adjustment cost parameter, are set at their calibrated values. (See Table I.) The inset to the figure shows that the contract multiplier is 1.8 with a demand curvature of -578 - which is twice as large as that used by Kimball (1995). But even if we set the curvature parameter 100 times higher at $\chi=-57,800$, we do not get a contract multiplier above 5. Furthermore, with this curvature parameter, equation (46) implies that a 0.5 percent increase in relative prices results in zero demand. Even with such an extremely convex demand function, when we raise $\sigma$ from 1 to 2.2 , the contract multiplier falls from a value above 4 to a value close to 0 . Again, this fall in the contract multiplier is due to the decrease in 
the adjustment cost parameter when $\sigma$ is raised. The empirical asset pricing literature suggests a risk aversion parameter significantly above 1, so that even this level of convexity of demand may not be enough to generate the requisite persistence. When we vary the parameters simultaneously within the ranges reported in Table III, we find that the largest value of the multiplier is 3.20 .

In panel B of Figure 2, we show how the multiplier varies as we vary the extent of decreasing returns to scale in the specific factors economy. We do so by varying the share of total income going to the fixed factor $\left(1-\alpha_{1}-\alpha_{2}\right)$. When varying this share, we keep $\alpha_{2} / \alpha_{1}$ equal to 2 and vary $\alpha_{1}$ and $\alpha_{2}$. When we do this, we see that the contract multiplier does not change much. When we vary the parameters simultaneously in the range reported in Table III, we find that the largest value of the multiplier is 4.17 .

Finally, we consider a model in which we incorporate near-perfect substitutes, convex demand, and specific factors in order to look for significant interaction effects. In Table II we report the results for this combined model at our calibrated values. The last column of Table II shows that combining these features raises the multiplier modestly to 1.81 from 1.55 (convex demand only) and 1.33 (specific factors only). When we vary the parameters simultaneously in the ranges reported in Table III, the maximum value of the contract multiplier is 4.17 and occurs with the same extreme parameter settings as the maximum of the specific factors economy.

One way to understand this is to note that any model with near-perfect substitutes gives a tiny contract multiplier. Thus, the only possible interesting interactions are between the convex demand and specific factors specifications. Panels C and D of Figure 2 show that the convex demand specification gives a large multiplier when the demand elasticity is small, while the specific factors specification gives a large multiplier when the demand elasticity is large. So when we combine the two features, we can either choose to make the elasticity small and get essentially the same multiplier as with convex demand alone or choose to make the elasticity large and get essentially the same multiplier as with specific factors alone. In no sense do these three variations tend to 
reinforce each other, and in no sense is the multiplier for the model with all three variations the sum of the multipliers for each one separately.

\section{Conclusion}

The central challenge to a theory of monetary business cycles is to find a solution to the persistence problem. Monetary economists have long searched for a mechanism which has a multiplier effect in the sense that small frictions lead to long periods of endogenous price rigidity and, hence, persistent output movements. Here we find that the staggered price-setting mechanism is not the long-sought solution.

One interpretation of our findings is that if 5 years of exogenous price stickiness is plausible, then conventional models used in the business cycle literature can generate persistent output fluctuations. With the amount of convexity in demand posited by Kimball (1995), or with extremely elastic demand and sizable departures from constant returns to scale, generating persistence requires

$2 \frac{1}{2}$ years of exogenous price stickiness. If one quarter of exogenous price stickiness is plausible, then generating persistence requires extraordinarily convex demand or extremely elastic demand.

Altogether, these findings suggest that mechanisms to solve the persistence problem must be found elsewhere. 
Department of Economics, University of Minnesota, Minneapolis, MN 55455, U.S.A.; Research Department, Federal Reserve Bank of Minneapolis, Minneapolis, MN 55480, U.S.A.; chari@ res.mpls.frb.fed.us,

Department of Economics, University of Pennsylvania, Philadelphia, PA 19104, U.S.A.; Research Department, Federal Reserve Bank of Minneapolis, Minneapolis, MN 55480, U.S.A.; and National Bureau of Economic Research, Cambridge, MA 02138, U.S.A.; pkehoe@res.mpls.frb.fed.us, and

Research Department, Federal Reserve Bank of Minneapolis, Minneapolis, MN 55480, U.S.A.; erm@ellen.mpls.frb.fed.us 


\section{REFERENCES}

Ball, Laurence, and David Romer (1989): "Are Prices Too Sticky?" Quarterly Journal of Economics, 104, 507-524.

_ (1990): "Real Rigidities and the Non-Neutrality of Money," Review of Economic Studies, 57, 183-203.

Basu, Susanto (1996): "Procyclical Productivity: Increasing Returns or Cyclical Utilization?" Quarterly Journal of Economics, 111, 719-751.

Basu, Susanto, and John G. Fernald (1994): "Constant Returns and Small Markups in U.S. Manufacturing," International Finance Discussion Paper 483, Board of Governors of the Federal Reserve System.

— (1995): "Are Apparent Productive Spillovers a Figment of Specification Error?" Journal of Monetary Economics, 36, 165-188.

Basu, Susanto, and Miles S. Kimball (1997): "Cyclical Productivity With Unobserved Input Variation," Working Paper 5915, National Bureau of Economic Research.

Blanchard, Olivier Jean (1990): "Why Does Money Affect Output? A Survey," in Handbook of Monetary Economics, vol. 2, ed. by Benjamin M. Friedman and Frank H. Hahn. Amsterdam: North-Holland, 779-835.

- (1991): "Price Asynchronization and Price-Level Inertia," in New Keynesian Economics, vol. 1, Imperfect Competition and Sticky Prices, ed. by N. Gregory Mankiw and David Romer. Cambridge, Mass.: MIT Press, 243-265.

Blanchard, Olivier Jean, and Stanley Fischer (1989): Lectures on Macroeconomics. Cambridge, Mass.: MIT Press.

Blanchard, Olivier Jean, and Nobuhiro Kiyotaki (1987): "Monopolistic Competition and the Effects of Aggregate Demand," American Economic Review, 77, 647-666.

Caplin, Andrew S., and John V. Leahy (1991): "State-Dependent Pricing and the Dynamics of 
Money and Output," Quarterly Journal of Economics, 106, 683-708.

Caplin, Andrew S., and Daniel F. Spulber (1987): "Menu Costs and the Neutrality of Money," Quarterly Journal of Economics, 102, 703-725.

Chari, V. V.; Patrick J. Kehoe; and Ellen R. McGrattan (1998): "Sticky Price Models of the Business Cycle: Can the Contract Multiplier Solve the Persistence Problem?" Research Department Staff Report 217, Federal Reserve Bank of Minneapolis.

Cho, Jang Ok, and Thomas F. Cooley (1995): "The Business Cycle With Nominal Contracts," Economic Theory, 6, 13-33.

Christiano, Lawrence J. (1988): “Why Does Inventory Investment Fluctuate So Much?” Journal of Monetary Economics, 21, 247-280.

Cooley, Thomas F., and Edward C. Prescott (1995): "Economic Growth and Business Cycles," in Frontiers of Business Cycle Research, ed. by Thomas F. Cooley. Princeton, N.J.: Princeton University Press, 1-38.

Dixit, Avinash K., and Joseph E. Stiglitz (1977): "Monopolistic Competition and Optimum Product Diversity," American Economic Review, 67, 298-308.

Fischer, Stanley (1977): "Long-Term Contracts, Rational Expectations, and the Optimal Money Supply Rule," Journal of Political Economy, 85, 191-205.

Kimball, Miles S. (1995): "The Quantitative Analytics of the Basic Neomonetarist Model," Journal of Money, Credit, and Banking, 27, 1241-1277.

King, Robert G., and Mark W. Watson (1996): "Money, Prices, Interest Rates, and the Business Cycle," Review of Economics and Statistics, 78, 35-53.

Lucas, Robert E., Jr. (1972): "Expectations and the Neutrality of Money," Journal of Economic Theory, 4, 103-124.

(1988): "Money Demand in the United States: A Quantitative Review," Carnegie-Rochester Conference Series on Public Policy, 29, 137-167. 
_ (1990): "Liquidity and Interest Rates," Journal of Economic Theory, 50, 237-264.

Lucas, Robert E., Jr., and Michael Woodford (1993): "Real Effects of Monetary Shocks in an Economy With Sequential Purchases," Working Paper 4250, National Bureau of Economic Research.

Mankiw, N. Gregory, and Lawrence H. Summers (1986): "Money Demand and the Effects of Fiscal Policies," Journal of Money, Credit, and Banking, 18, 415-429.

McGrattan, Ellen R. (1996): "Solving the Stochastic Growth Model With a Finite Element Method," Journal of Economic Dynamics and Control, 20, 19-42.

Ohanian, Lee E., and Alan C. Stockman (1994): "Short-Run Effects of Money When Some Prices Are Sticky," Federal Reserve Bank of Richmond Economic Quarterly, 80, 1-23.

Phelps, Edmund S., and John B. Taylor (1977): "Stabilizing Powers of Monetary Policy Under Rational Expectations," Journal of Political Economy, 85, 163-190.

Rotemberg, Julio J. (1996): "Prices, Output, and Hours: An Empirical Analysis Based on a Sticky Price Model," Journal of Monetary Economics, 37, 505-533.

Stock, James H., and Mark W. Watson (1993): "A Simple Estimator of Cointegrating Vectors in Higher Order Integrated Systems," Econometrica, 61, 783-820.

Taylor, John B. (1980): "Aggregate Dynamics and Staggered Contracts," Journal of Political Economy, 88, 1-23.

Woodford, Michael (1996): "Control of the Public Debt: A Requirement for Price Stability?" Working Paper 5684, National Bureau of Economic Research.

Yun, Tack (1996): "Nominal Price Rigidity, Money Supply Endogeneity, and Business Cycles," Journal of Monetary Economics, 37, 345-370. 


\section{Notes}

${ }^{1}$ We thank Susanto Basu, Miles Kimball, Julio Rotemberg, Michael Woodford, and especially Nancy Stokey for helpful comments. Chari thanks the NSF for financial support. Kehoe thanks the NSF and the Ronald S. Lauder Foundation for financial support. Materials related to this paper are available at http://minneapolisfed.org/research/sr/sr217.html. The views expressed herein are those of the authors and not necessarily those of the Federal Reserve Bank of Minneapolis or the Federal Reserve System.

${ }^{2}$ Our setup draws on some of the work on earlier general equilibrium sticky price models, including, for example, Blanchard and Kiyotaki (1987) and Ball and Romer (1989, 1990). Our work is also closely connected to some recent work embedding sticky prices in business cycle models; see Ohanian and Stockman (1994), Cho and Cooley (1995), King and Watson (1996), Rotemberg (1996), Woodford (1996), and Yun (1996). For a slightly different approach using fixed costs, see Caplin and Spulber (1987) and Caplin and Leahy (1991).

${ }^{3}$ To calculate the contract multiplier for our economies in which output is measured at discrete intervals, we need a measure of the half-life of output for such economies. We calculate the halflife by finding the first date at which output is lower than half its impact value and then linearly interpolate output between this date and the previous date. 


\section{Table I}

\section{Model Parameters}

\begin{tabular}{ll}
\hline \hline Model & Parameter Values \\
\hline A. Benchmark Economy & \\
Preferences & $\beta=0.97^{\frac{T}{N}}, \omega=0.94, \quad \eta=0.39$, \\
& $\psi=1.5, \quad \sigma=1$ \\
Production & $\alpha=0.33, \quad \theta=0.9$ \\
Capital Accumulation & $\delta=1-0.92^{\frac{T}{N}}, \quad b$ adjusted \\
Money Growth & $\rho=0.57^{\frac{4 T}{N}}$ \\
B. Three Variations & \\
Near-Perfect Substitute Preferences & $\kappa=0.0002, \quad \xi=0.00011$, \\
& $\nu=0.0002, \quad \omega_{1}, \omega_{2}$ adjusted \\
Convex Demand & $\varepsilon=10, \quad \chi=-289$ \\
Specific Factors & $\alpha_{1}=0.22, \quad \alpha_{2}=0.44$ \\
\hline
\end{tabular}

Note: In our experiments, $T=1 / 4$ unless otherwise noted. 


\section{Table II}

The Contract Multiplier With Various Intertemporal Links

\begin{tabular}{|c|c|c|c|c|}
\hline \multirow[b]{2}{*}{ Economy $^{a}$} & \multicolumn{4}{|c|}{ Types of Intertemporal Links } \\
\hline & None & Only Money & Only Capital & Both \\
\hline \multicolumn{5}{|l|}{ Benchmark } \\
\hline 2 cohorts, iid money growth & 0.90 & 0.90 & 1.02 & 1.05 \\
\hline 13 cohorts, serially correlated money growth & 1.01 & 0.87 & 1.11 & 0.99 \\
\hline \multicolumn{5}{|l|}{ Near-Perfect Substitute Preferences ${ }^{b}$} \\
\hline 2 cohorts, iid money growth & 21.97 & 20.00 & 1.07 & 0.50 \\
\hline 13 cohorts, serially correlated money growth & 139.10 & 22.72 & 8.31 & 0.13 \\
\hline \multicolumn{5}{|l|}{ Convex Demand } \\
\hline 2 cohorts, iid money growth & 2.17 & 2.17 & 1.57 & 1.62 \\
\hline 13 cohorts, serially correlated money growth & 3.79 & 2.44 & 1.76 & 1.55 \\
\hline \multicolumn{5}{|l|}{ Specific Factors } \\
\hline 2 cohorts, iid money growth & 1.43 & 1.43 & 1.30 & 1.30 \\
\hline 13 cohorts, serially correlated money growth & 1.82 & 1.54 & 1.59 & 1.33 \\
\hline \multicolumn{5}{|l|}{ Combined Model } \\
\hline 2 cohorts, iid money growth & 1.96 & 1.96 & 1.75 & 1.75 \\
\hline 13 cohorts, serially correlated money growth & 3.26 & 2.19 & 2.39 & 1.81 \\
\hline
\end{tabular}

a See Table I for parameter values. No capital link implies that the capital share is 0 . No money link implies that the interest elasticity of money is 0 . If money growth is serially correlated, then $\rho=0.57^{\frac{1}{13}}$; otherwise, it is 0 .

${ }^{b}$ If there is no money link, we assume that $M / \bar{P}=c$. 


\section{Table III}

\section{Parameter Ranges and the Results of Sensitivity Analysis}

\begin{tabular}{|c|c|c|}
\hline Economy & Parameters & Values \\
\hline \multirow[t]{7}{*}{ Benchmark } & Interest Elasticity $(\eta)$ & {$[0.2,0.5]$} \\
\hline & Capital Share $(\alpha)$ & {$[0.22,0.44]$} \\
\hline & Weight on Leisure in Utility $(\psi)$ & {$[0.11, \quad 9]$} \\
\hline & Risk Aversion $(\sigma)$ & {$\left[\begin{array}{ll}1, & 10\end{array}\right]$} \\
\hline & Demand Elasticity $(\varepsilon)$ & {$[5,300]$} \\
\hline & Serial Correlation of Money Growth $(\rho)$ & {$[0,0.99]$} \\
\hline & $\begin{array}{l}\text { Maximum Multiplier } \\
(\eta=0.2, \alpha=0.22, \psi=9 \\
\sigma=1, \varepsilon=300, \rho=0.96)\end{array}$ & 3.05 \\
\hline \multirow[t]{2}{*}{ Convex Demand } & Demand Curvature $(\chi)$ & {$[-289,11]$} \\
\hline & $\begin{array}{l}\text { Maximum Multiplier } \\
(\eta=0.2, \alpha=0.22, \psi=9 \\
\sigma=1, \varepsilon=5, \rho=0.96, \chi=-289)\end{array}$ & 3.20 \\
\hline \multirow[t]{3}{*}{ Specific Factors } & Capital Share $\left(\alpha_{1}\right)$ & {$[0.22,0.44]$} \\
\hline & Labor Share $\left(\alpha_{2}\right)$ & {$[0.33,0.78]$} \\
\hline & $\begin{array}{l}\text { Maximum Multiplier } \\
\begin{array}{l}(\eta=0.2, \psi=9, \sigma=1, \varepsilon=300 \\
\left.\rho=0.96, \alpha_{1}=0.22, \alpha_{2}=0.33\right)\end{array}\end{array}$ & 4.17 \\
\hline
\end{tabular}


FIGURE 1.- Sensitivity analysis for the benchmark economy.
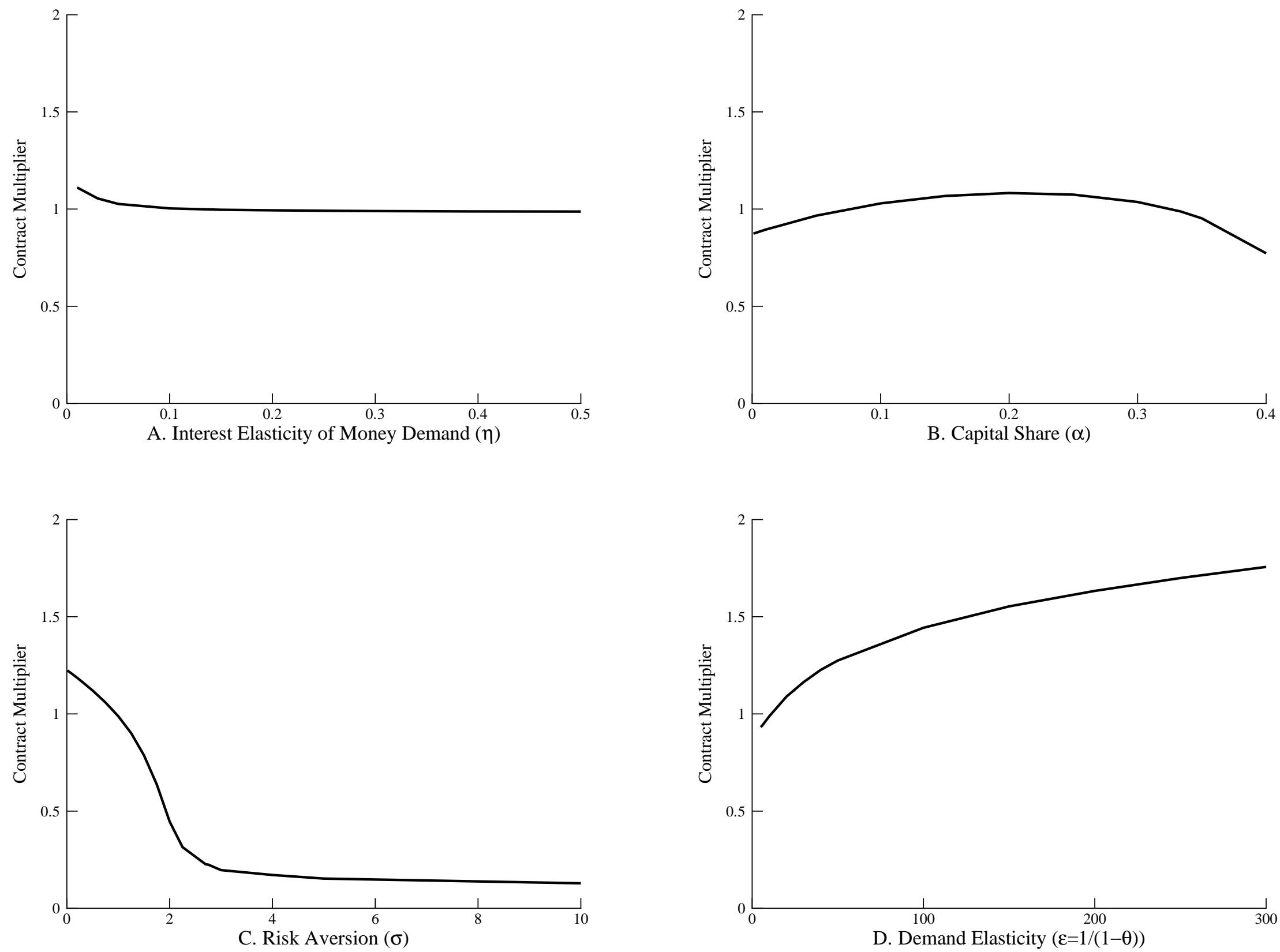
FIGURE 2.- Sensitivity analysis for two economies.

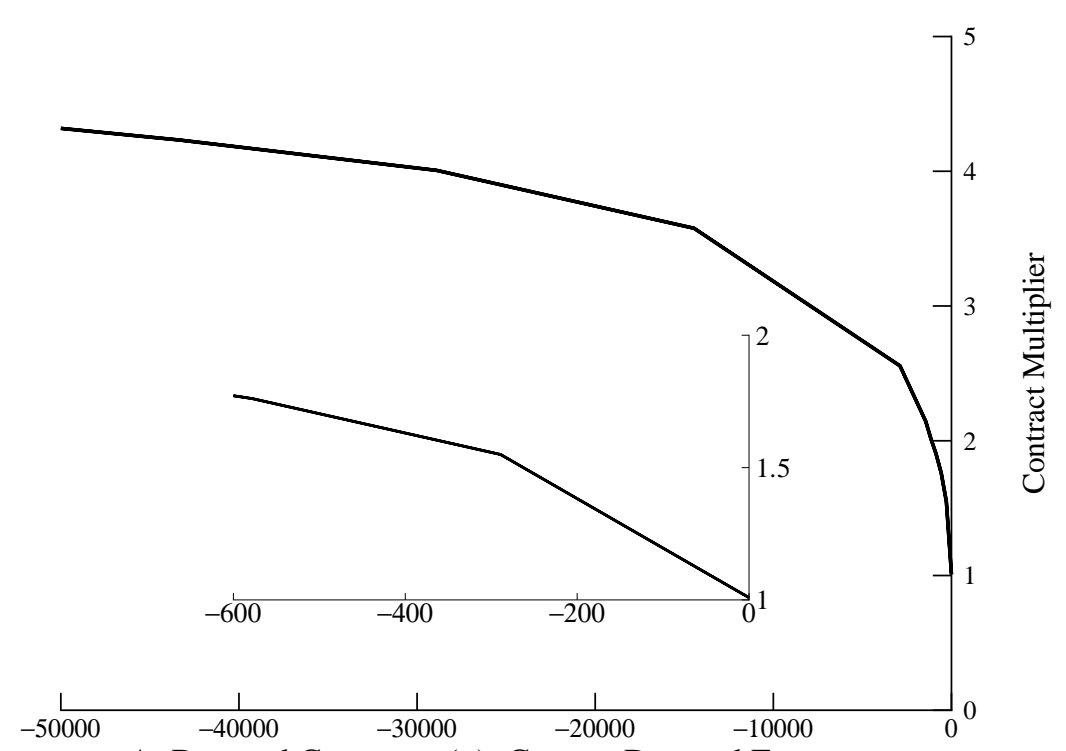

A. Demand Curvature $(\chi)$, Convex Demand Economy

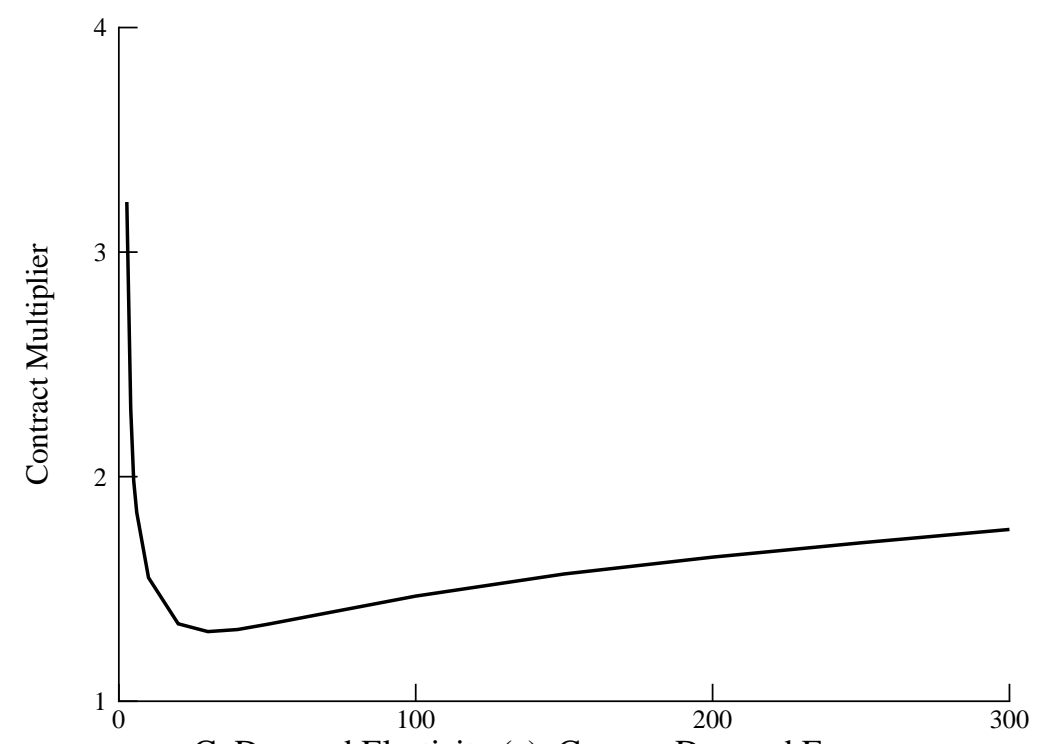

C. Demand Elasticity $(\varepsilon)$, Convex Demand Economy

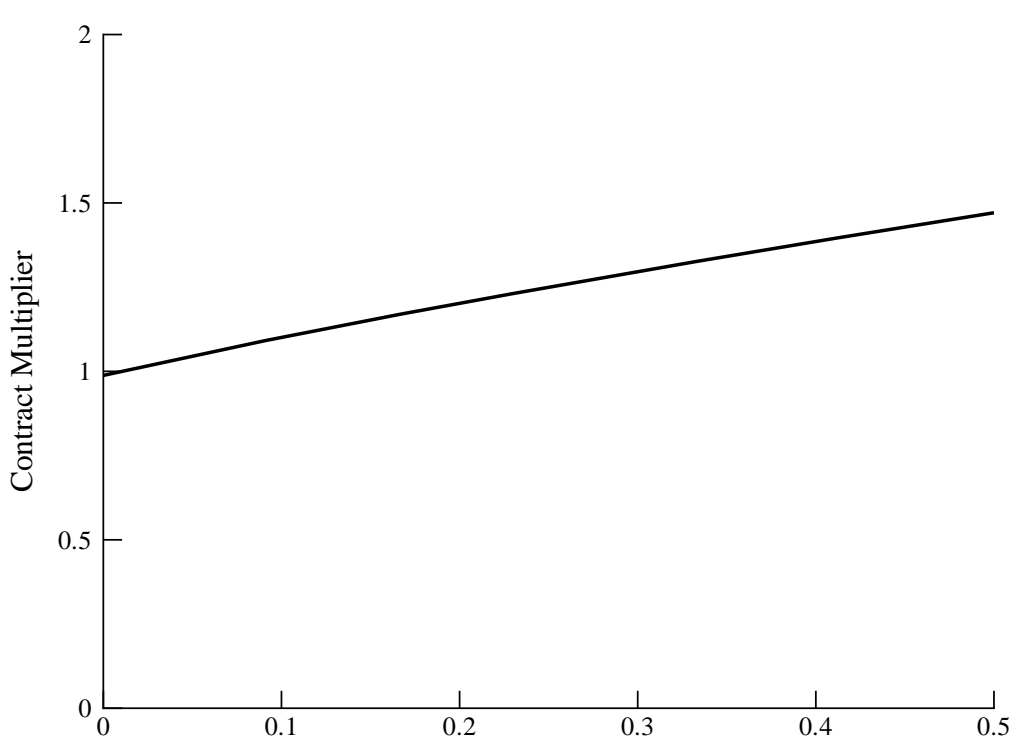

B. Fixed Factor's Share of Income $\left(1-\alpha_{1}-\alpha_{2}\right)$, Specific Factors Economy

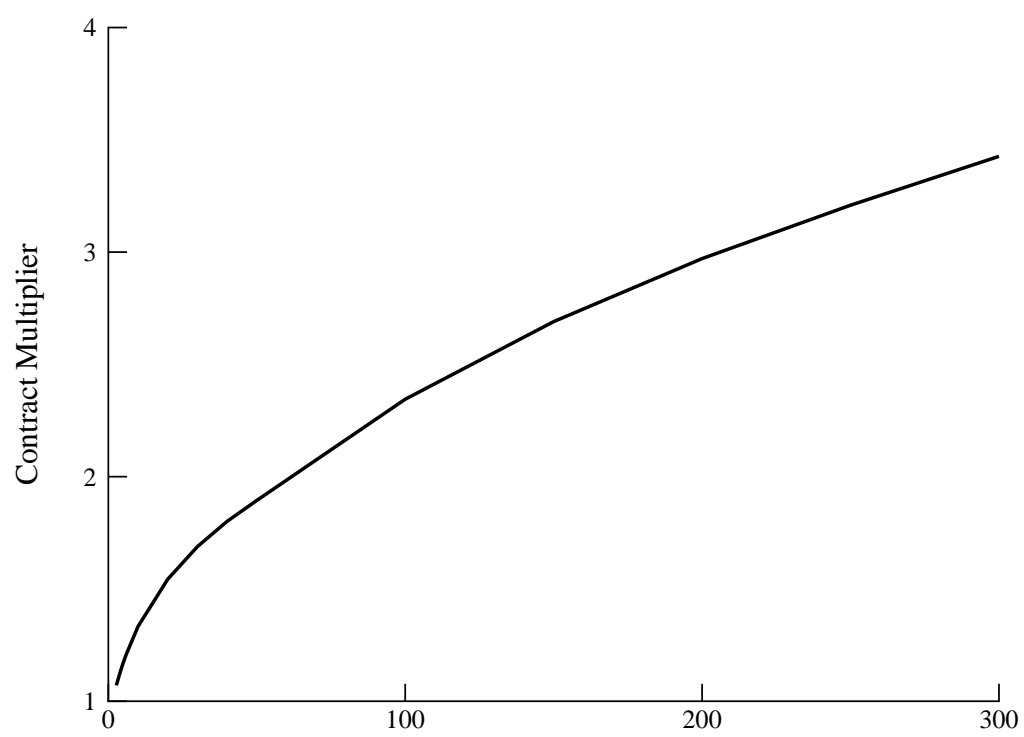

D. Demand Elasticity $(\varepsilon)$, Specific Factors Economy 